\title{
A study on terrain-induced tropical cyclone looping in East Taiwan: case study of Typhoon Haitang in 2005
}

\author{
Tien-Chiang Yeh $\cdot$ Ling-Feng Hsiao $\cdot$ Der-Song Chen • \\ Kang-Ning Huang
}

Received: 14 July 2010/Accepted: 11 June 2011/Published online: 30 June 2011

(C) The Author(s) 2011. This article is published with open access at Springerlink.com

\begin{abstract}
A mesoscale mountain such as the Central Mountain Range (CMR) of Taiwan can considerably affect the motion and the structure of an approaching tropical cyclone in very complicated ways. Many studies have presented and explained the mechanism for the change of moving speed, track deflection, or track discontinuity. In the past, the tracks of Typhoon Mary (1965), Tropical Cyclone Polly (1993), and Typhoon Haitang (2005) have a looping motion prior to making landfall on Taiwan. When the looping occurs, the timing and the intensity of the typhoon to affect Taiwan can be very different from the one moving with smooth track. It is very important to have a correct forecast for disaster mitigation operations. However, the mechanism causing such looping has not been fully understood. In this study, the case of Typhoon Haitang is examined. The radar reflectivity diagrams are used to illustrate looping in its track. By applying piecewise potential vorticity inversion analysis and numerical model simulations, it is shown that the looping motion of Typhoon Haitang near Taiwan resulted from the CMR terrain effect. When Typhoon Haitang approaches Taiwan and its circulation encounters the CMR, the terrain induces a cyclonic vortex in the lee side of the mountain over southeast of Taiwan. This terrain-induced vortex interacts with Typhoon Haitang in a way similar to the binary vortex interaction. The two vortex centers rotate around their system center, which causes looping of Typhoon Haitang.
\end{abstract}

Keywords Typhoon - Looping track - Piecewise potential vorticity inversion · Typhoon-terrain interaction · Terrain-induced vortex

T.-C. Yeh $(\bowtie) \cdot$ D.-S. Chen · K.-N. Huang

Central Weather Bureau, 64 Gongyuan Road, Taipei, Taiwan, ROC

e-mail: yeh@cwb.gov.tw

L.-F. Hsiao

Taiwan Typhoon and Flood Research Institute, Taipei, Taiwan, ROC 


\section{Introduction}

The motion, intensity, and structure of a tropical cyclone can be significantly modified by the topography when the cyclone passes over a mesoscale mountain range. Such a phenomenon is often observed near Taiwan (e.g., Wang 1980) as the Central Mountain Range (CMR) with peaks higher than 3,500 $\mathrm{m}$ is located in the center of this mesoscale island. In other regions such as the Zulu island in Philippines and the Cordillera in Central Hispaniola, an orographic effect on tropical cyclone motion and structure changes is also well known (e.g., Brand and Blelloch 1974; Bender et al. 1987).

Several scenarios of tropical cyclone track deflections caused by the CMR have been summarized by Wang (1980) after examining more than 100 tropical cyclones that invaded Taiwan from 1949 to 1977 . He showed cases in which the track of the tropical cyclone had only minor deflections when it crossed the mountain as well as cases of tropical cyclones that were significantly affected by the CMR. Wang classified these tropical cyclone tracks into eight categories according to tropical cyclone moving direction and the way the center passed over the mountain. He noticed that the center of tropical cyclone either continuously or discontinuously moved across the CMR. He also found many cases in which westward-approaching tropical cyclones moved northward upstream of CMR. One or several secondary low centers would form when the tropical cyclone approached. If a secondary low develops while the original typhoon center dissipates over the topography, the secondary low gradually becomes the dominant one, which results in a discontinuous track of the tropical cyclone crossing over the CMR.

Chang (1982) numerically simulated a tropical cyclone passing over the CMR in a cyclonic direction. The basic flow in low levels is blocked, and the air parcels have to move around the mountain while the upper-level flow experiences little changes. The center of the tropical cyclone is thus not vertically aligned, and the lower-level center accelerates and moves northward/southward when it approaches/passes the mountain range. Chang suggested that the cumulus heating near and over the mountain is responsible for the generation and maintenance of the cyclonic circulation around the mountain. The cyclonic circulation steers the low-level center in a cyclonic direction to pass the mountain.

Bender et al. (1987) simulated more realistic intensity and track changes as the tropical cyclone approaches and depart from Taiwan. Formation of a secondary low was also simulated, and they indicated that the enhanced and deflected steering flow due to some unknown vortex-barrier interaction caused the tropical cyclone motion change. They also showed that a region of dry air forms as the descending flow over the mountain is advected into the storm, which is responsible for the weakening of the system before it makes landfall.

Yeh and Elsberry (1993a) numerically simulated upstream track deflections of the westward-approaching tropical cyclones to a CMR-like barrier that can be summarized in three regions. For a region of far upstream, the barrier does not affect the approaching tropical cyclone. In their region B, which is about $250-400 \mathrm{~km}$ upstream of the barrier, the track deflections are in same sense but have larger magnitudes than those of a basic flow approaching the barrier. In their region $\mathrm{C}$, which extends from about $250 \mathrm{~km}$ to the barrier, the track deflections are different from a simple barrier-blocking effect on the basic flow. Yeh and Elsberry explained that the larger track deflections in region B are due to the superposition of the outer cyclone circulation on the basic flow, which enhances the blocking effect of the barrier. As the tropical cyclone moves closer to the barrier, the modifications of the tropical cyclone structure become more severe, and the barrier effect can induce an asymmetric flow across the vortex center. This asymmetric flow leads to a deceleration and deflection of the storm in the region $\mathrm{C}$. They also showed barrier effect 
depended on the tropical cyclone moving speed and intensity. The upstream track deflections tend to be larger for weaker and slowly moving storms. Later, Yeh and Elsberry (1993b) simulated that more intense and rapidly moving tropical cyclones are more likely to cross directly over the CMR and thus maintain a continuous track. The weaker and more slowly moving vortices are more likely to be dissipated on the upstream side and result in a discontinuous track across the barrier. They also suggested the vortex reorganization downstream of the barrier may form either from a downward extension of the upper-level remnants of the circulation or from an upward development of a secondary vortex at lower levels that forms and is shed westward.

Lin et al. (1999) found in their numerical simulations that the circulation center of a typhoon approaching a mountain range tends to be deflected southward as a result of orographic blocking effect. Kuo et al. (2001) also found in their shallow-water model simulations with a quiescent fluid that a vortex becomes trapped near the isolated barrier and follows a clockwise path. They explained such a vortex motion as an equivalence betaeffect.

To identify control parameters for diagnosing the continuity and deflection of cyclone tracks across a mesoscale mountain range, Lin et al. (2005) reexamined previous studies in combination with additional numerical model simulations of tropical cyclones passing over the CMR. They developed a conceptual model with three responses of the westwardmoving vortex to the orographic forcing. With weak orographic blocking, the vortex is deflected slightly northward upstream of the barrier, and the vortex follows a continuous track across the mountain. With moderate orographic blocking, the vortex upstream is deflected in the same direction as in the weak orographic blocking case. However, a secondary vortex forms on the southwest slope of the barrier that results in a discontinuous track of the vortex across the mountain. With strong orographic blocking, the vortex again follows a discontinuous track across the mountain, but the approaching vortex is deflected southward and the secondary vortex forms on the northwest slope of the mountain range.

In terms of disaster prevention and mitigation, accurate forecasts of the movement and structure of an approaching tropical cyclone are very crucial for the weather service. The structure change of the tropical cyclone due to topography such as CMR can directly influence the amount of rainfall and the strength of the wind. The track deflection and changes in translation speed can also vary the timing and the areas having heavy rainfall and strong winds. The above studies of motion changes as a tropical cyclone approaches are guidance for forecasters in predicting tropical cyclone impacts.

Two very interesting cases were selected from the historical database of the tropical cyclone tracks in Taiwan area collected by Shieh et al. (1998). Both Typhoon Mary (1965) and Tropical Cyclone Polly (1993) had a cyclonic loop before landfall on eastern Taiwan. In August 2005, the westward-moving Typhoon Haitang also made a loop before landfall on eastern Taiwan. Jian and Wu (2008) simulated the case with a mesoscale numerical model and reported the looping motion of Typhoon Haitang was due to the CMR effect. They demonstrated the looping motion is correlated with the inner-core asymmetric winds of Haitang. They explained the southward defection as Haitang approached Taiwan was due to the formation of a low-level northerly jet on the western side of the eyewall caused by a channeling effect, and the northward deflection later in the looping motion was due to the decrease in wind speed on the western side of the storm caused by surface friction.

In summary, various studies explain that the effects of the CMR topography on the approaching tropical cyclone are due to barrier-blocking effects, channeling effect, or an equivalent of beta-effect. The tropical cyclone track may be deflected northward or southward with an accelerated or decelerated in translation speed. However, the 
mechanism for the backward movement of the tropical cyclone when it approaches a mountain has not been carefully addressed. Persistence of a typhoon in the same area for a long time can greatly increase the impacts, especially with extreme rainfall accumulation.

To study the cause of an unusual 'loop' of a tropical cyclone prior to making landfall on eastern Taiwan, data from Typhoon Haitang were collected. The typhoon track, synoptic environment, and the radar reflectivity observed from the radar network in Taiwan are discussed in Sect. 2. In Sect. 3, the numerical model is introduced. The simulations are discussed in Sect. 4. Summary and conclusions are in Sect. 5.

\section{Typhoon Haitang}

Typhoon Haitang was the fifth named tropical cyclone in western North Pacific Ocean during 2005. According to the Central Weather Bureau (CWB), the system became a tropical storm at $00 \mathrm{UTC}$ July 12 east of $150^{\circ} \mathrm{E}$ (see Fig. 1) and strengthened to become a typhoon 38 h later. Liao (2006) noted that Typhoon Haitang first had a southward component and reached its southernmost position near $19^{\circ} \mathrm{N}, 135^{\circ} \mathrm{E}$ before moving toward Taiwan in west-northwestward direction. By 06 UTC July 16, Typhoon Haitang had strengthened to a super typhoon after moving into a more favorable environment.

The typhoon track overlaid on the 7-day mean 500-hPa geopotential heights is shown in Fig. 2. It indicates the low-pressure area associated with the typhoon. Two other major weather systems influencing the typhoon are the subtropical high pressure system to the north of the storm and the weak trough over the land near $100^{\circ} \mathrm{E}$. Typhoon Haitang generally moved parallel to the 5,880-m-height contour when the storm was west of $135^{\circ} \mathrm{E}$. However, the center was deflected from the smooth track after 18 UTC July 17 (see inset in Fig. 1). Haitang moved southward first, then back to the north at 00 UTC July 18 before it made landfall on northeastern Taiwan at about 06 UTC July 18.

In the mosaic of reflectivity diagrams from the CWB radar network (Fig. 3), an eye is clearly visible when the center was about $250 \mathrm{~km}$ east to the coast at 12 UTC July 17. Several rain bands formed within the system. The eye was still identifiable when a portion of the storm moved inland, as the center was at $24^{\circ} \mathrm{N}, 122^{\circ} \mathrm{E}$ near the coast line at 21 UTC

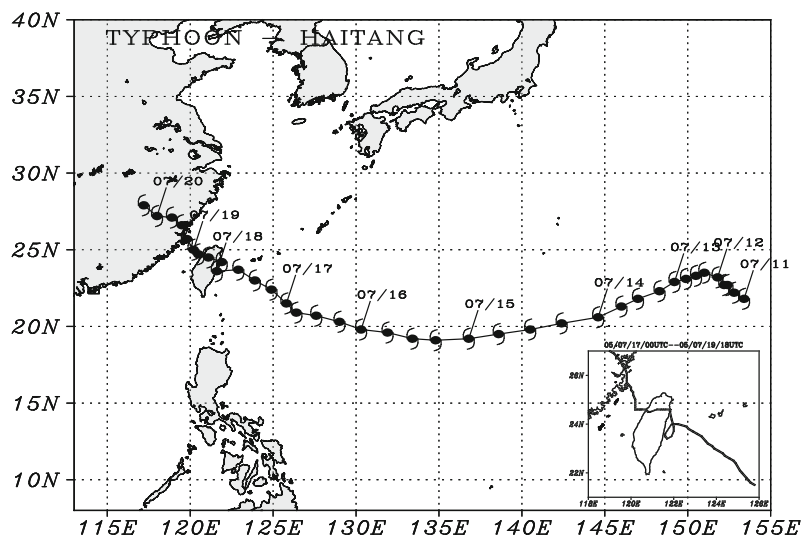

Fig. 1 Track of Typhoon Haitang with typhoon symbols are in 6-h intervals. Positions at 00 UTC are indicated with the date (month/day). Track from 00 UTC July 17 to 18 UTC July 192005 in the inset illustrates the looping motion east of Taiwan 


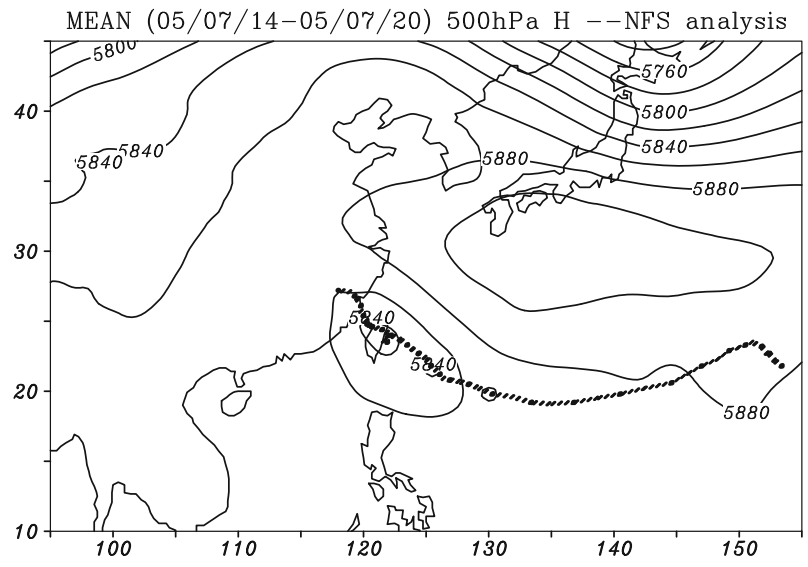

Fig. 2 Track (dots) of Typhoon Haitang superposed on the 7-day mean (14th to 20th July 2005) 500-hPa geopotential field
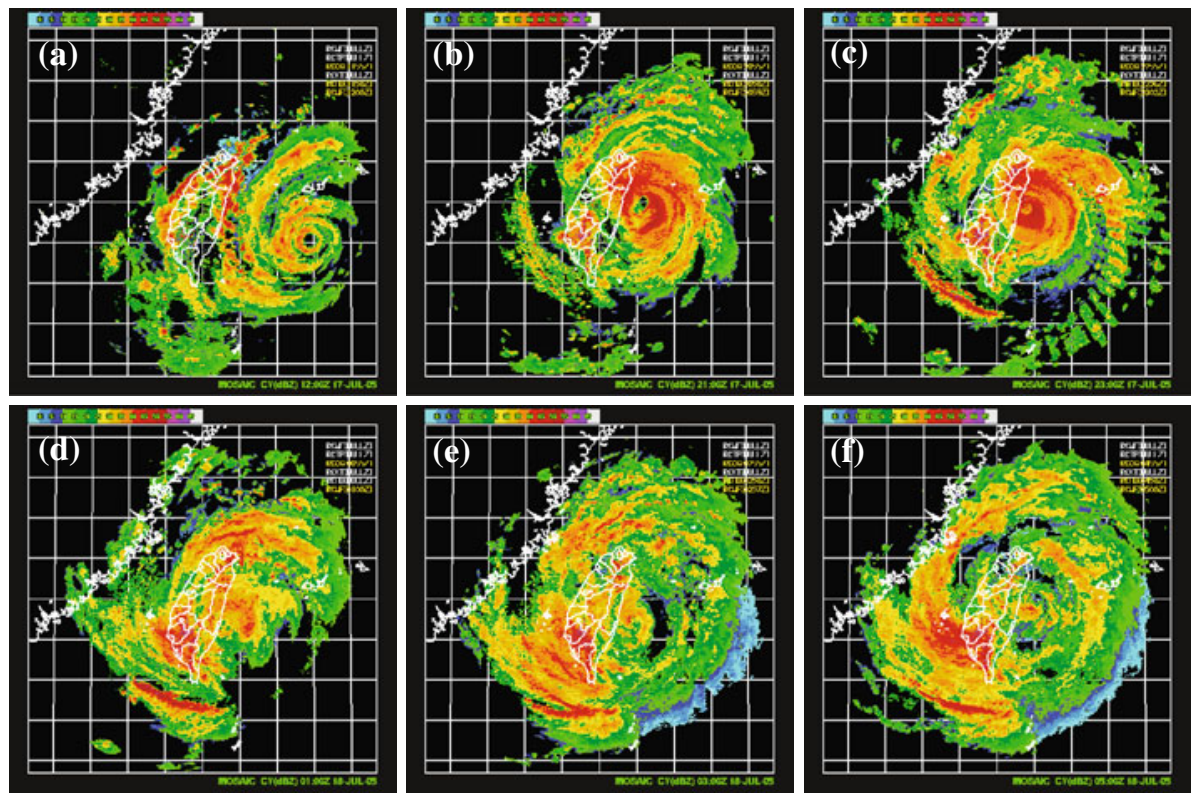

Fig. 3 Radar reflectivity at a 12 UTC 17th, b 21 UTC 17th, c 23 UTC 17th, d 01 UTC 18th, e 03 UTC 18th, and f 05 UTC 18th July 2005 during the approach and cyclonic loop of Typhoon Haitang

July 17 (Fig. 3b). Two hours later (Fig. 3c), the center moved southward and the eye became unclear. At 01 UTC July 18 (Fig. 3d), the center was near $23^{\circ} \mathrm{N}, 121.5^{\circ} \mathrm{E}$ and the eye was not identifiable from the radar. The center then moved northward to near $23.5^{\circ} \mathrm{N}$, $122^{\circ} \mathrm{E}$ at 03 UTC July 18 (Fig. 3e) and near $24^{\circ} \mathrm{N}, 122^{\circ} \mathrm{E}$ at 05 UTC July 18 (Fig. 3f) before it made landfall around 05 UTC July 18 (not shown). Using the 10-min radar images and local surface observations, the CWB was able to track the center of Typhoon Haitang as it moved with a cyclonic loop prior to making landfall (inset, Fig. 1). Discussion of the looping motion of Typhoon Haitang was also given in Jian and Wu (2008). 

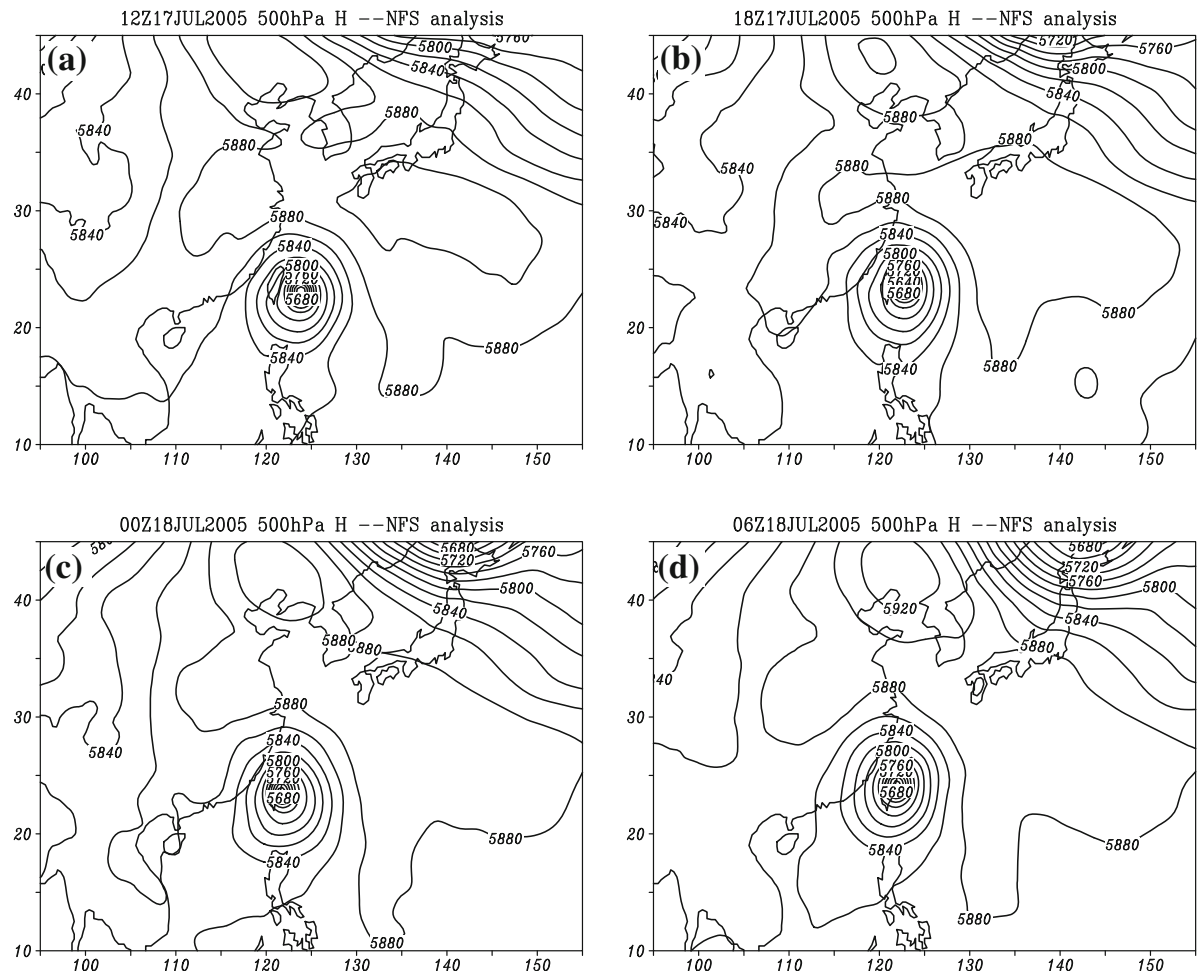

Fig. 4 Evolution of 500-hPa geopotential heights (20 m contour interval) at a 12 UTC 17 th, b 18 UTC 17th, c 00 UTC 18th, and d 06 UTC 18th July 2005

The evolution of the 500-hPa geopotential height field from 12 UTC July 17 to 06 UTC July 18 is presented in Fig. 4. As in Fig. 2, the subtropical high pressure and the middle latitude trough are dominant features. At 12 UTC July 17 (Fig. 4a), an area of geopotential heights higher than 5,880 $\mathrm{m}$ was over northeastern China. Another high-pressure cell was over the ocean south of Japan. A trough with geopotential height lower than 5,860 m was over western China. At 18 UTC July 17 (Fig. 4b), the general features of the geopotential field remained about the same except that the area of geopotential heights higher than 5,880 m was much smaller. As shown in Fig. 5a, the geopotential heights over almost the entire area decreased at this time, with the exceptions being the areas over the southwestern corner of the domain, in the middle latitude trough, and to the east of Typhoon Haitang. At 00 UTC July 18 (Fig. 4c), the area enclosed by the 5,880-m geopotential height contour had enlarged, and the geopotential heights to the north of the storm over the Korean Peninsula and northern China had increased (Fig. 5b). At 06 UTC July 18, the geopotential heights over the Korean Peninsula and northern China continued to increase, which is also indicated by the trends in Fig. 5c. Therefore, this synoptic scale analysis does not support that the southward/northward movement of Haitang before/after 00 UTC July 18 could be attributed to a strengthening and weakening of the high-pressure system.

Many studies (e.g., Shapiro 1996; Wu et al. 2004, and others) had used the piecewise potential vorticity inversion analysis (Davis 1992) to diagnose dominant factors that contribute to the motion of tropical cyclones. Application of this analysis technique in this case showed that the subtropical high had a major contribution in steering Typhoon 
Fig. 5 500-hPa geopotential height change (5-m contour interval) a between 12 UTC 17th and 18 UTC 17 th, b between 18 UTC 17th and 00 UTC 18th, and c between 00 UTC 18 th and 06 UTC 18th July 2005. Areas of positive geopotential height change are shaded

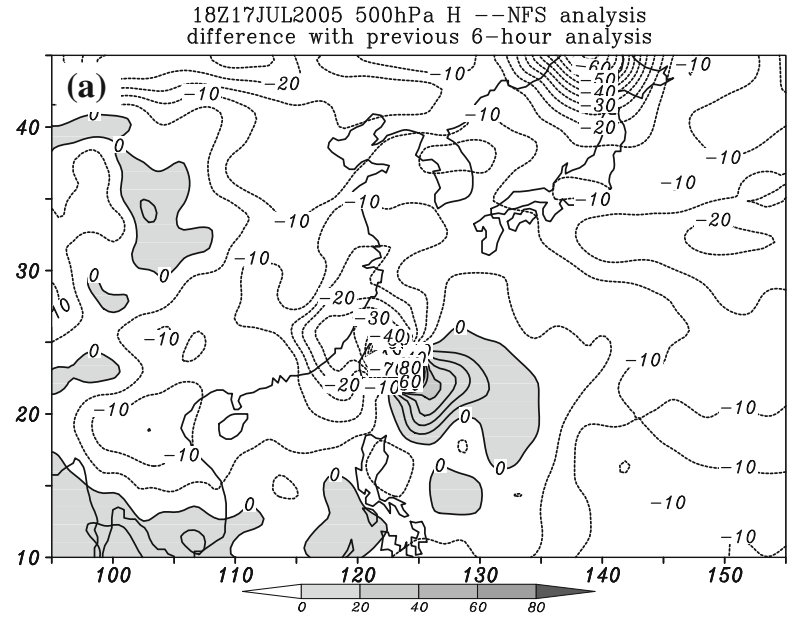

00Z18JUL2005 500hPa $\mathrm{H}--\mathrm{NFS}$ analysis difference with previous 6 -hour analysis

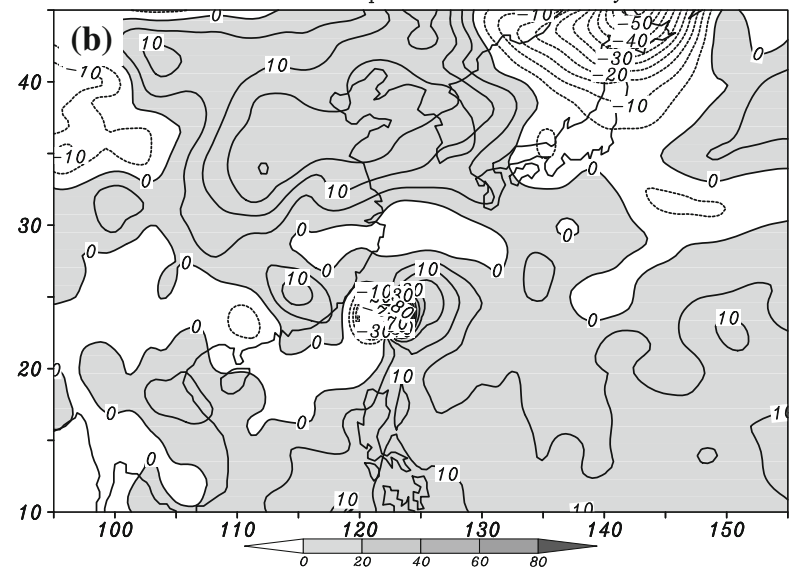

06Z18JUL2005 500hPa H - -NFS analysis difference with previous 6 -hour analysis

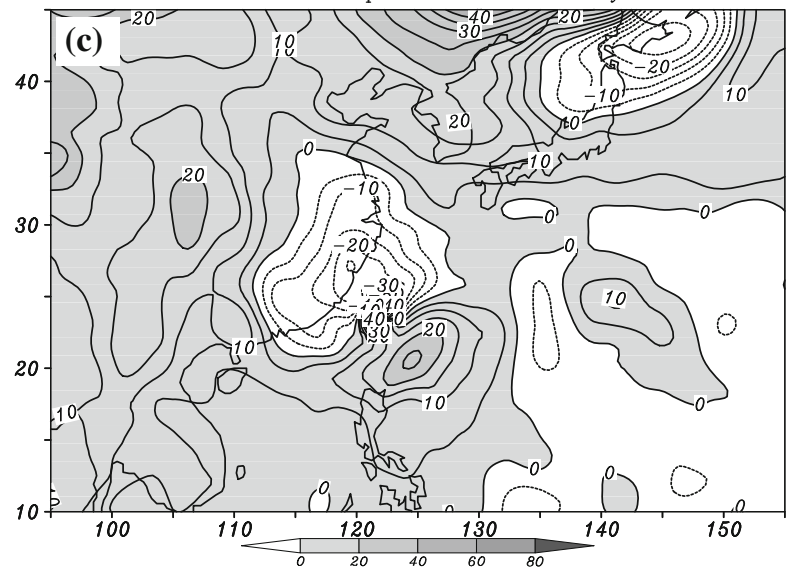


Haitang northwestward, while the middle latitude trough tended to steer it northward. However, these steering tendencies could not explain the looping motion east of Taiwan.

\section{Numerical model}

Numerical simulations were employed to explain the synoptic scale factors contributed to the looping, southward and eastward, motion of Typhoon Haitang when it got close to Taiwan. The numerical model is the operational CWB regional model called non-hydrostatic forecast system (NFS). The NFS is a model in terrain-following mass coordinates without the hydrostatic approximation. By adding extra terms and equations for the nonhydrostatic contribution, Liou et al. (2009) were able to formulate the complete governing equation of the compressible atmosphere in the mass coordinate very similar to the primitive equation system in the sigma-p coordinate. A split time integration is used in which the hydrostatic part of the model is integrated first and followed by the nonhydrostatic part of calculation. In that way, the major computer codes of the terrainfollowing mass coordinate non-hydrostatic model are shared with the sigma-p coordinate hydrostatic model, which speeded up the computation and made it easier to maintain the model. The model physics include Harshvardhan et al. (1987) radiation parameterization scheme, TKE- $\varepsilon$ closure planetary boundary layer parameterization scheme (Detering and Etling 1985), Kuo type of cumulus parameterization scheme (Kuo 1974), and simple cloud/ice explicit for microphysics process by Zhao et al. (1997). More discussion of the model may be found in Liou et al. (2009) and Hsiao et al. (2009).

The operational version of NFS is implemented on 30 vertical layers with a triple-nested domain of horizontal resolutions $45 / 15 / 5 \mathrm{~km}$. To initiate a forecast, observations are analyzed in the outer two domains with an optimal interpolation analysis scheme. An initialization procedure with incremental update cycles is included. After data analysis, the initial fields on the middle domain are interpolated to the inner domain. The lateral boundary conditions for NFS are provided by the CWB Global Forecast System (Liou et al. 1997). At the time of Typhoon Haitang, the CWB Global Forecast System was integrated on 30 vertical layers with a horizontal resolution of about $60 \mathrm{~km}$ (T179).

A bogus vortex procedure is applied to improve the initial position, intensity, and structure of the tropical cyclone when it is within the NFS model domain. The procedure includes a vortex relocation technique by Liou (2004) that uses a flow decomposition method similar to that developed by Kurihara et al. (1995). The first-guess tropical cyclone circulation is translated to the observed position if the first-guess circulation position is displaced from the observed position by more than one grid interval. This modified firstguess fields with the relocated tropical cyclone is part of the analysis increments in the incremental update cycle data assimilation. With this relocation method, large corrections to the first guess due to the position error can be avoided and the analyzed tropical cyclone circulation is more reasonable without twisting the center even with incremental update cycles. To better represent the intensity and structure of the cyclone, a bogus vortex of 41 synthetic observations are added for the objective analysis. The synthetic observations depend on the observed storm size, central pressure, and the maximum wind speed of the tropical cyclone. More detailed discussion of the NFS vortex relocation and vortex bogus is available in Liou (2004) and Hsiao et al. (2010). With this bogus procedure, NFS has skill in predicting the tropical cyclone movement. The average forecasting error of 21 tropical cyclone tracks in 2005 was $112 / 208 / 304 \mathrm{~km}$ for the 24/48/72-h forecasts (Chen et al. 2006). 


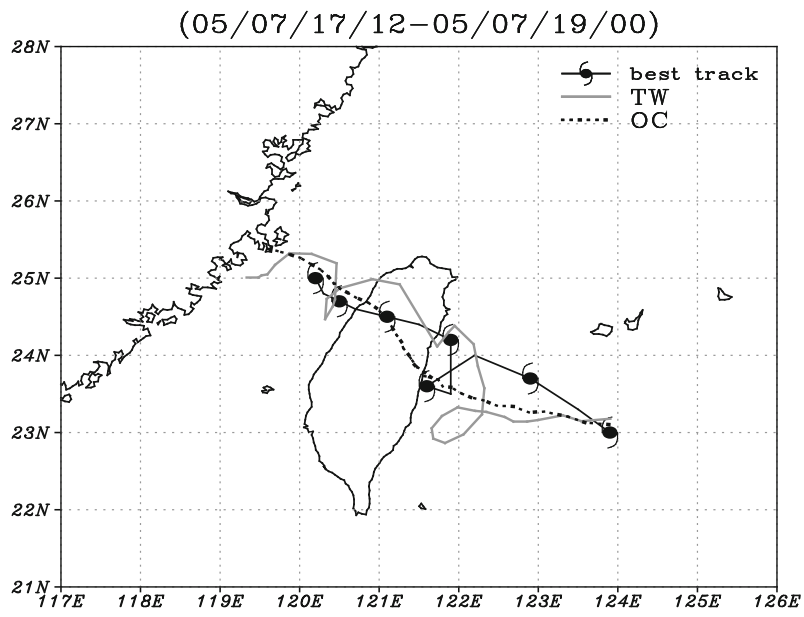

Fig. 6 The NFS model track forecasts with the Taiwan topography included (TW, solid no symbols) and the ocean-only (OC, dotted) simulation of Typhoon Haitang beginning at 12 UTC 17 July 2005. The observed track at 3-hourly resolution is shown with typhoon symbols every $6 \mathrm{~h}$

\section{Simulations and discussion}

The 48-h NFS track forecast of Typhoon Haitang started at 12 UTC July 17 is shown in Fig. 6. The model forecast has a similar looping in the track before the typhoon made landfall on northeastern Taiwan even though the forecast track was too far westward during the first $6 \mathrm{~h}$.

The piecewise potential vorticity inversion analysis was carried out for different parts of the disturbance as in $\mathrm{Wu}$ et al. (2004) to examine the possible factors contributed to the looping motion (Fig. 7). The steering velocity is computed as the deep-layer-mean wind

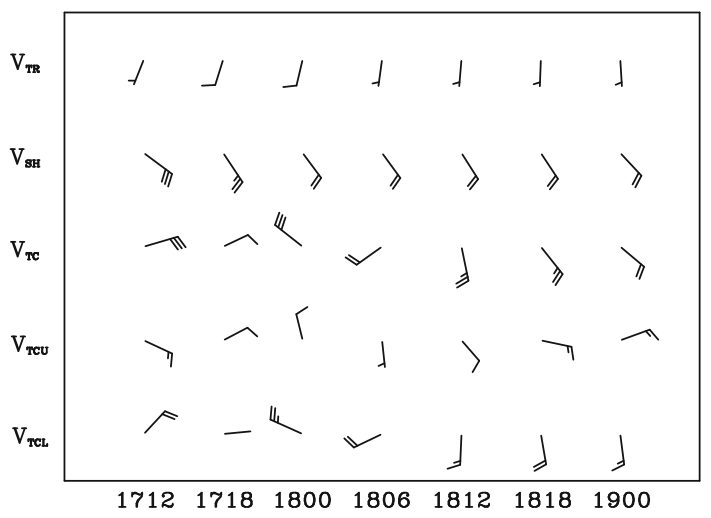

Fig. 7 Steering velocities $V_{\mathrm{TR}}, V_{\mathrm{SH}}$, and $V_{\mathrm{TC}}$ attributed to the middle latitude trough, subtropical high, and the vortex, respectively, deduced from piecewise potential vorticity inversion analysis of the NFS operational forecast fields each $6 \mathrm{~h}$ beginning at 12 UTC 17 July 2005. The $V_{\mathrm{TCU}}$ and $V_{\mathrm{TCL}}$ velocities represent the contributions from upper $(500 \mathrm{hPa}$ and above) and lower layer (below $500 \mathrm{hPa}$ ) of the vortex. For these velocities, a full bar is $1 \mathrm{~m} / \mathrm{s}$, and the directions of east, west, south, and north are directed toward the right, left, down, and up sides, respectively 
vector between 925 and $300 \mathrm{hPa}$ averaged within a $3^{\circ}$ latitude circle around typhoon center. As discussed in Sect. 2, the steering velocities associated with the middle latitude trough $V_{\mathrm{TR}}$ (line 1 in Fig. 7) and the subtropical high $V_{\mathrm{SH}}$ (line 2 in Fig. 7) would tend to advect the typhoon to the north and to the northwest, respectively, and have about the same magnitude throughout the period. The steering velocity inversed from the Haitang motion $V_{\mathrm{TC}}$ (line 3 in Fig. 7) shifted gradually from west-southwestward at the beginning, to southeastward at 00 UTC July 18, then northeastward at 06 UTC, and northward at 12 UTC. Finally, the vortex had an effect to steer itself northwestward. It was during the period from 22 UTC July 17 to 00 UTC July 18 when $V_{\mathrm{TC}}$ had stronger southward component, Haitang moved southward. In the next $6 \mathrm{~h}$ when $V_{\mathrm{TC}}$ had stronger eastward components, Haitang gradually moved eastward, northeastward, and northward to form a looping track. Separating the vortex steering into effects due to the upper ( $500 \mathrm{hPa}$ and above, $V_{\mathrm{TCa}}$, line 4 in Fig. 7 ) and lower ( $V_{\mathrm{TCb}}$, line 5 in Fig. 7 ) parts of the vortex, the major contribution to the vortex's eastward motion away from the CMR at 00 UTC July 18 is from the lower part of the vortex. This result showed that the major factor that causes the looping motion of Typhoon Haitang is lying within the typhoon vortex and in the lower atmosphere. This result is consistent with Jian and Wu (2008), who found the average asymmetric flow within the inner core $(100 \mathrm{~km}$ radius from the center) of the storm was well correlated with the looping motion of Typhoon Haitang.

To examine whether this particular vortex structure contribution to motion resulting in the center looping is due to the topography effect of Taiwan, a simulation was conducted in which the Taiwan island was removed and replaced by the ocean, and thus will be designated as OC. This simulation was begun with a series of 6-h interval update cycles beginning at 12 UTC July 16 instead of 12 UTC July 17 because the first-guess fields contain terrain-induced disturbances that will be passed on to the initial fields through the analysis cycle even though the topography has been replaced by ocean. The OC simulation typhoon track (Fig. 6) is slightly to the north of that in the topography-included (TW) forecast in the initial $6 \mathrm{~h}$. This southward deflection of track is consistent with the simulations from Yeh and Elsberry (1993a). After that period, excluding the island Taiwan in the OC simulation results in a vortex track that smoothly passes the area with Taiwan island topography removed instead of looping.

The looping motion of Typhoon Haitang has also simulated by Jian and Wu (2008). They explained that the southward defection as Haitang approached Taiwan was due to the formation of a low-level northerly jet on the western side of the eyewall caused by a channeling effect of CMR, and the northward deflection later in the looping motion was due to the decrease in wind speed on the western side of the storm caused by surface friction. However, how come the track deflection would gradually change from southward, to eastward, to northward has not been discussed. In addition, the channeling effect and the friction effect both would exist in most cases of typhoon approaching Taiwan; how come the number of cases of looping motion typhoon is very rare has not been addressed.

To study the mechanism for the looping motion of Typhoon Haitang (Fig. 6), the fields from TW forecast are carefully compared with those from the OC simulation. The major differences between these two fields are in the lower levels of the typhoon near Taiwan, which is consistent with the findings in piecewise potential vorticity inversion analysis. The 925-hPa winds at 12 UTC July 17 indicate (Fig. 8) the circulation center of Typhoon Haitang in both TW forecast and OC simulation is about 2 degrees to the east of Taiwan. Cyclonic flows around the center are very symmetric and extend to the China coast. Excluding the island of Taiwan in the OC simulation, the cyclonic circulation is similar to the idealized vortex. However, the cyclonic flow near Taiwan is modified with the island 
Fig. 8 Wind vectors at $925 \mathrm{hPa}$ at 12 UTC July 17 from a the terrain-included (TW) forecast, and $\mathbf{b}$ the OC simulation. The scale $(\mathrm{m} / \mathrm{s})$ of the wind vectors is below each panel
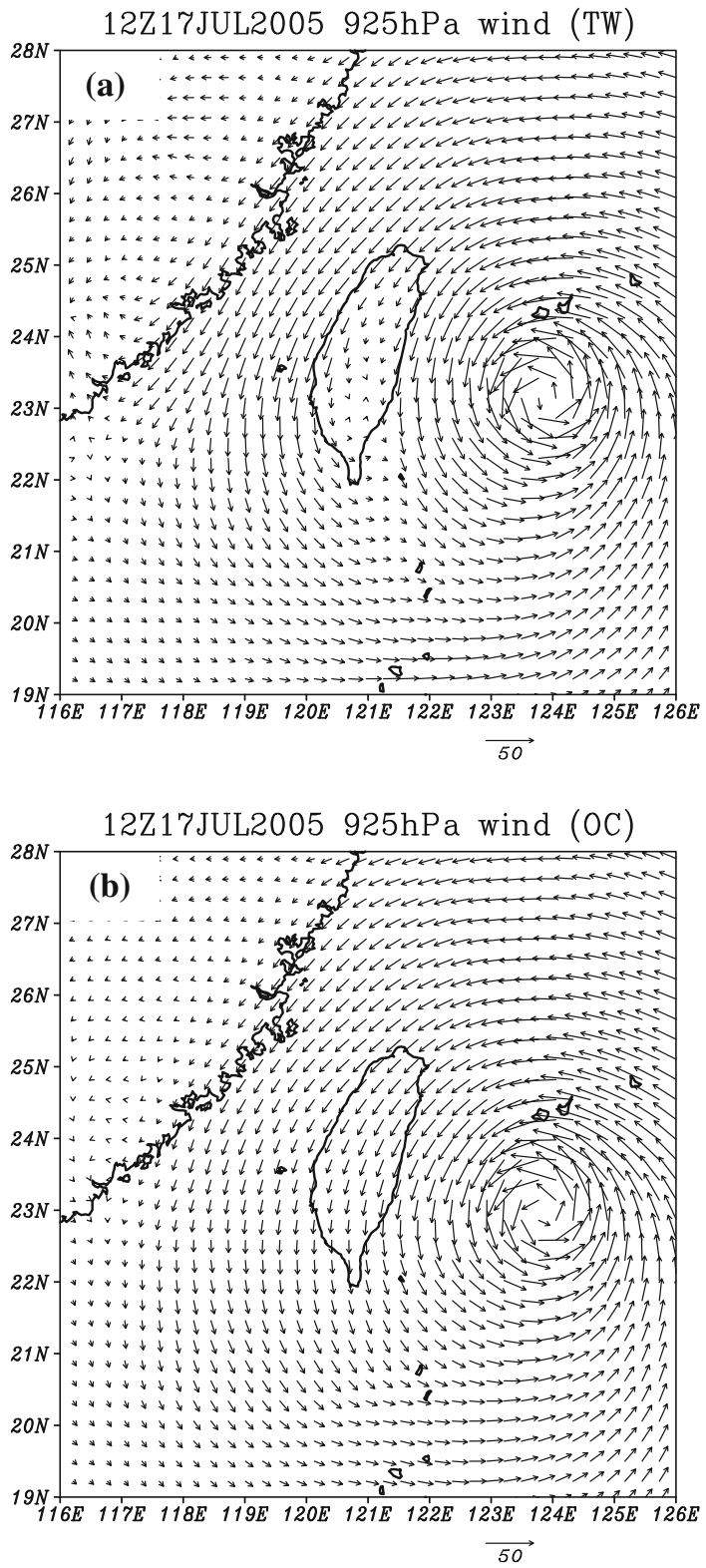

included. The wind speeds over Taiwan and on the lee side of the mountain are decelerated, and the flow over the Taiwan Strait is accelerated. These flow modifications are depicted in Fig. 9 as the difference in the 925-hPa wind vectors and vorticities between the TW forecast and the OC simulation. West of Taiwan, stronger northerly flows are found over the Strait. Over the center of the island and the lee side of the mountain, the northerly flows are decelerated, which is represented as southerly wind anomalies in Fig. 9. This distribution of the flow indicates the island modifies the Typhoon Haitang's circulation by inducing a pair of cyclonic and anticyclonic gyres with positive and negative vorticities on 


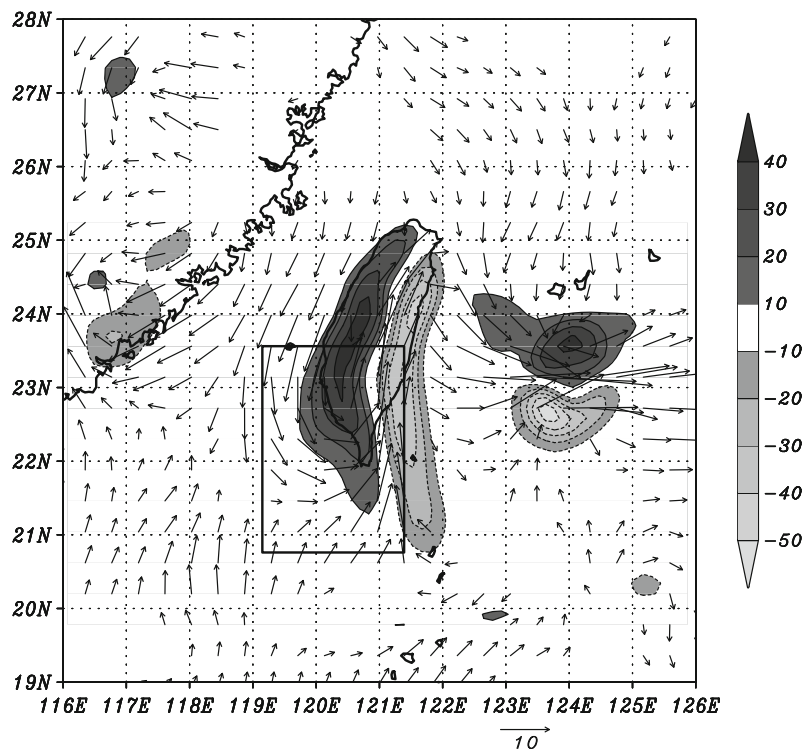

Fig. 9 The differences in the 925-hPa wind vectors and vorticity between the terrain-included (TW) forecast and the OC simulation at 12 UTC July 17. A wind vector scale $(\mathrm{m} / \mathrm{s})$ is at the bottom, and the vorticity scale $\left(* 10^{-5}\right)$ is on the right. The square shows the area where the fields will be used for the OD simulation (see text)

the western and eastern sides of Taiwan, respectively. In upstream of the island, the westerly wind anomalies can be seen from Fig. 9. It shows that with Taiwan terrain included the easterly advection flow to the motion of Haitang is slowed down. This phenomenon is similar to the blocking effect of CMR discussed by Yeh and Elsberry (1993a).

At 18 UTC July 17 (Fig. 10), which is $6 \mathrm{~h}$ after the simulation started, the typhoon vortex in the OC simulation has translated to the west. A large portion of the inner vortex has maintained about the same structure as in Fig. 8 because it has moved into the area where the island has been replaced by ocean. In the control experiment (TW), the cyclonic flow of Typhoon Haitang is being deflected by the mountainous topography. Northerly flows in advance of the center are accelerated over Taiwan Strait and decelerated over Central Taiwan. As the Haitang center moves closer to the island at 18 UTC, the flow deceleration area on the leeside shifts northward and is located closer to the typhoon center. The effect of the Taiwan topography on the typhoon vortex is indicated in Fig. 11 by similar terrain-induced perturbation fields as in Fig. 9. Because the locations of the vortex center in TW and in OC simulations are now different at $18 \mathrm{UTC}$, the terraininduced perturbation fields are calculated by shifting the OC simulated fields so that the vortex center positions in the TW forecast and OC simulation are collocated. In other words, we assumed that the typhoon vortex maintained as in OC simulation if the model excludes the island Taiwan. A pair of terrain-induced gyres is near the typhoon center (Fig. 11). The cyclonic gyre to the southwest of the center is stronger than the anticyclonic gyre at the northeast.

Similar terrain-induced perturbation fields have been calculated every hour from 12 UTC July 17 to 06 UTC July 18. Positions of the typhoon center and the terrain-induced 
Fig. 10 Similar to Fig. 8, except for the 6-h forecast of $925-\mathrm{hPa}$ wind vectors from a the operational forecast with topography, and $\mathbf{b}$ the $\mathrm{OC}$ simulation
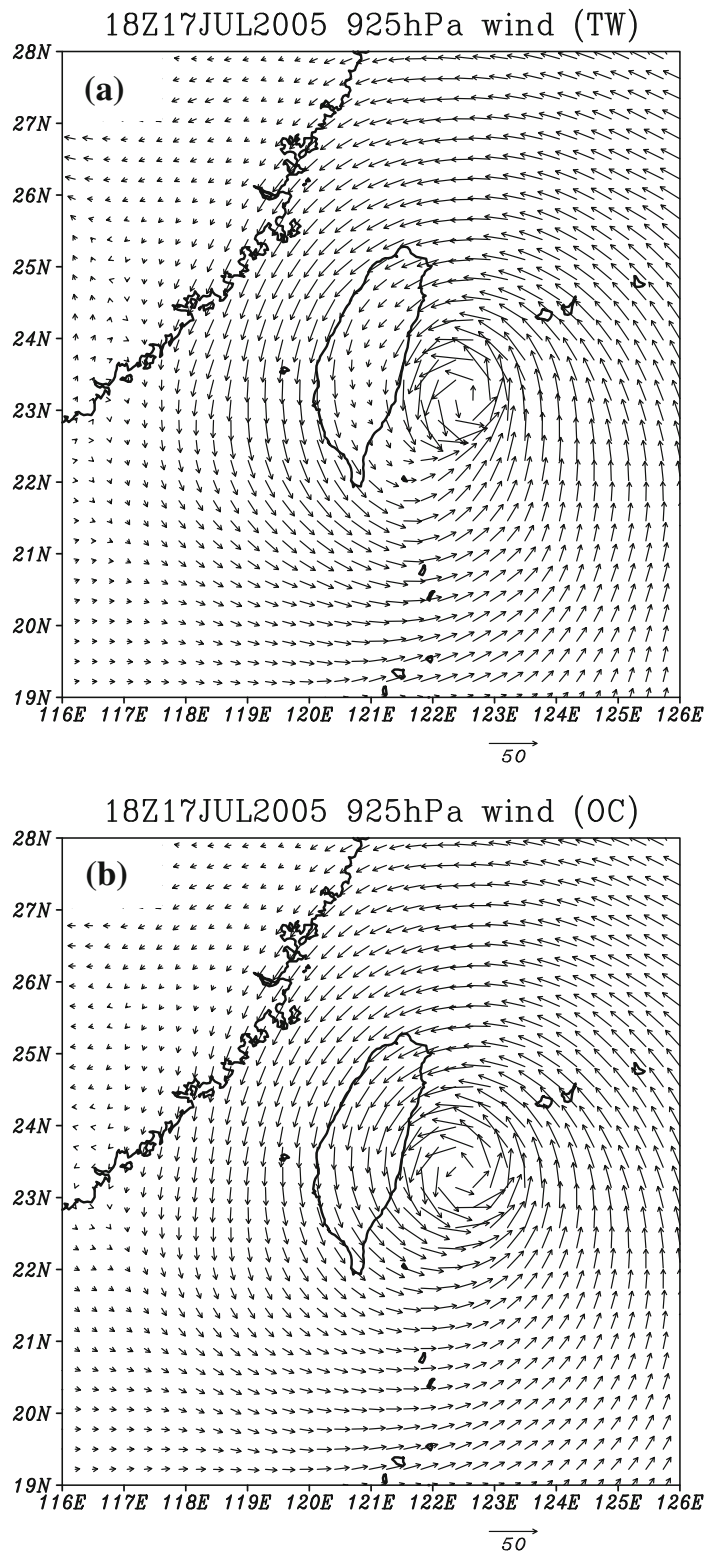

cyclonic gyre center are plotted in Fig. 12a. While the Haitang center made a loop east to Taiwan, the perturbation cyclonic gyre center shifts cyclonically around the typhoon center. If the westward-moving mean speed $(3 \mathrm{~m} / \mathrm{s}$ easterly in Fig. $12 \mathrm{~b}$ and $6.5 \mathrm{~m} / \mathrm{s}$ southsouthwesterly in Fig. 12c) is removed, a pattern similar to the binary vortex interaction (e.g., Chang 1983; Lander and Holland 1993) is seen in Fig. 12b, c. The center of Haitang and the center of the terrain-induced gyre rotate around their system center when they shift with the basic flow.

To further demonstrate that the terrain-induced perturbation can cause the looping motion of an approaching typhoon, another simulation was conducted in which a portion of 


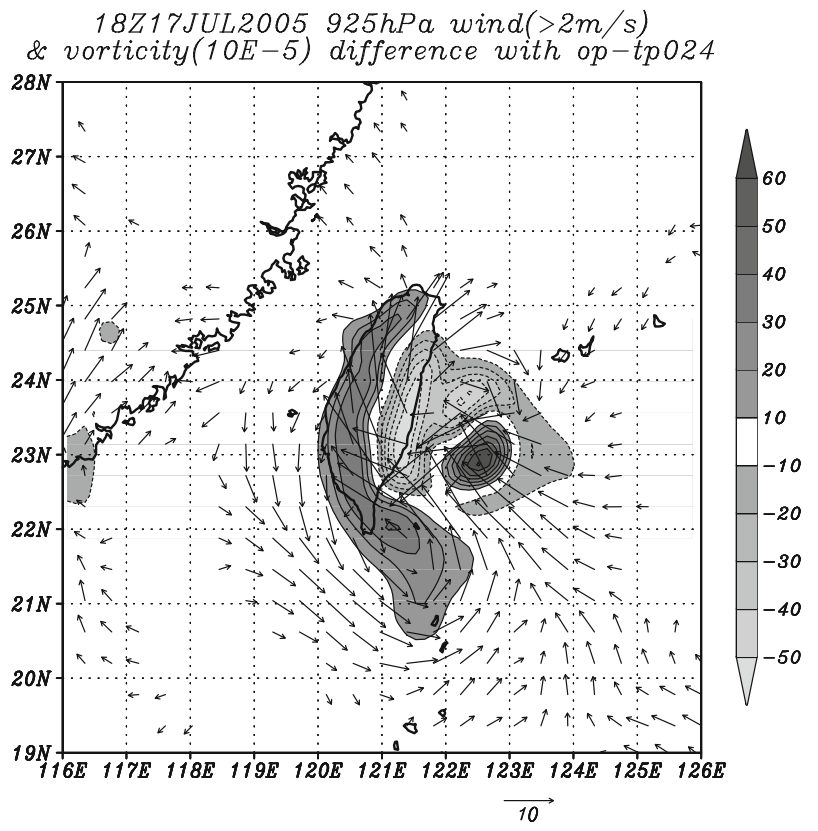

Fig. 11 Similar to Fig. 9, except for the differences in 925-hPa wind vectors and vorticity for the 6-h forecast fields

the terrain-induced perturbation was added to the initial field of the OC simulation, which is the labeled OD (ocean with disturbance). That is, even though the topography of Taiwan has been excluded, a part of the terrain-induced perturbation has been inserted at its proper position in the initial fields at the initial time. The area and the structure of the terraininduced perturbation that were added are shown in the square of Fig. 9. Initially, the typhoon's movement in OD simulation (Fig. 13) is very similar to that in OC simulation, except that some small displacements of the center from the smooth track are found in OD simulation. As the typhoon moves closer to the position of the terrain-induced perturbation, cyclonic looping of the center is simulated before the typhoon motion to the north terminates the interaction with the imposed terrain-induced perturbation. Since the terraininduced perturbation imposed was obtained from model initial time (12 UTC July 17) when Haitang center was about 2 degrees east of the coastline, the amplitude of the perturbation is smaller than that when Haitang moved closer to the island (e.g., Fig. 11). This explains the amplitude of the looping track in OD simulation is smaller than that in the TW forecast.

A note is that the OD simulation does not include the Taiwan topography. The terraininduced perturbation imposed only contents the portion over southern Taiwan (Fig. 9). Therefore, the terrain-induced southerly jet due to channeling effect discussed by Jian and $\mathrm{Wu}$ (2008) will not occur in OD simulation. Another important difference of OD simulation and TW forecast is the imposed perturbation in OD simulation will not stay at or near the "terrain". Rather, the perturbation will be advected downstream by the Haitang circulation, similar to an eddy shedding off after it is generated. The simulation demonstrates that without topography but with an imposed perturbation in a favorable location can cause the center looping of an approaching typhoon. 
Fig. 12 a Hourly positions of the typhoon center (smaller digital number) and the terraininduced cyclonic gyre center (larger digital number). The number indicates number hours of forecast. b Similar to a except the center positions were plotted in relative to the center location of 19 UTC (number 7) and the mean advection of $3 \mathrm{~m} / \mathrm{s}$ westward was removed. c Similar to $\mathbf{b}$ except the center positions were plotted in relative to the center location of 03 UTC 18 July (number 15), and the mean advection of $6.5 \mathrm{~m} / \mathrm{s}$ northnortheastward was removed
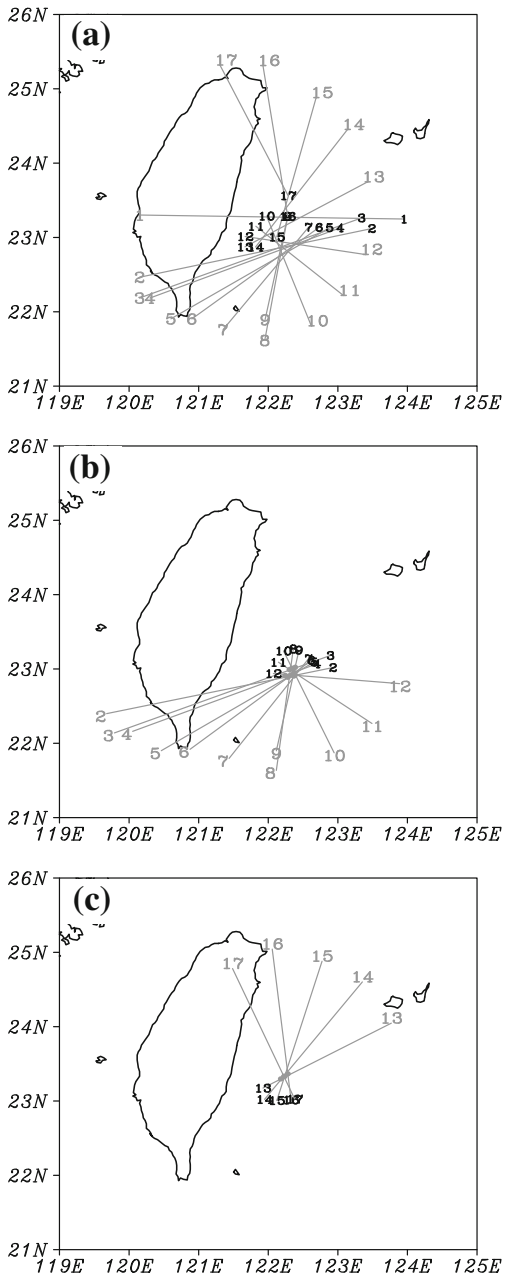

The above numerical studies explore a possibility that a terrain-induced gyre sheds off from the island could interact with the approaching typhoon. The interaction result a looping track of the typhoon. Many studies (e.g., Smolarkiewicz et al. 1988; Ueyoshi and Han 1991) discussed the shed eddies leeward from an island. Grubisic et al. (1995) used a shallow-water model and discussed the instabilities of the Hawaiian wake. The condition for eddy to shed off in typhoon approaching Taiwan may be much more complicated than that in a simple flow environment, particularly for case of the eddy with enough intensity for interacting with typhoon to occur. More restrictions in the condition for eddy to shed off, less cases would be observed with looping motion when typhoon approaches Taiwan.

\section{Summary and conclusions}

Many studies have shown the Central Mountain Range in Taiwan can significantly affect the motion and the structure of an approaching tropical cyclone. The influences include 


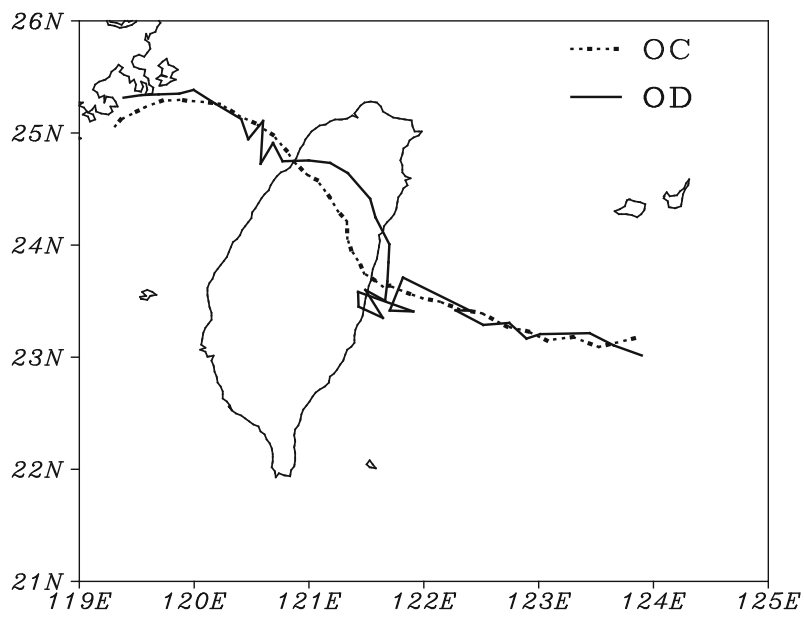

Fig. 13 Similar to Fig. 6, except for the NFS model track forecasts of the OC and OD (ocean with disturbance) simulations

varying the tropical cyclone translation speed or deflecting the system from its original track. In some favorable conditions, one of the secondary vortices induced by the terrain may be enhanced to replace the original tropical cyclone center, which then leads to discontinuous track for the tropical cyclone to pass Taiwan.

Two westward-moving tropical cyclones, Typhoon Mary (1965) and Tropical Cyclone Polly (1993), are examples of cyclones that had looping tracks east to Taiwan prior to making landfall. A similar example of looping was well documented by radar reflectivity when Typhoon Haitang approached Taiwan in July 2005. Jian and Wu (2008) reported the looping motion of Typhoon Haitang was due to Taiwan terrain effect and suggested that the barrier-blocking and surface friction effects caused such looping motion.

To further examine the mechanism caused the looping of Typhoon Haitang, numerical modeling results were analyzed. The regional forecast model of the Central Weather Bureau predicted a similar center looping of Typhoon Haitang in its operational forecast from 12 UTC July 17. Application of a piecewise potential vorticity inversion analysis identified that the major factor contributing to the eastward and northward motion part of the motion was not related to the synoptic environment flow. Rather, it was the modification of the vortex structure, and notably the lower layer of the vortex is the most important. Jian and $\mathrm{Wu}$ (2008) also showed the asymmetric winds in inner core of Typhoon Haitang are related to its looping motion.

A simulation with the island of Taiwan removed and replaced by the ocean showed the Typhoon Haitang would pass through the area with a smooth track if the Taiwan Island was excluded from the model. Detailed analysis of the differences in the control and the simulation with the topography revealed how the lower-layer circulation was modified by the island of Taiwan when Haitang approached the terrain. Northerly flow was enhanced over the Taiwan Strait but was decelerated over Central Taiwan and on the leeside of the mountain. Assuming that the typhoon vortex in a simulation excluding the island of Taiwan is the non-disturbed structure, the deviation of the field from this non-disturbed structure may be treated as the terrain-induced structure. In particular, a cyclonic terraininduced gyre was formed near Taiwan when Haitang approached that then sheds off the terrain and interacted with Haitang similar to a binary vortex interaction. Indeed, the two 
circulations rotate around cyclonically an intermediate point in a way that can explain the looping motion of Haitang east of Taiwan prior to the landfall.

A simulation with the island of Taiwan removed but imposed a terrain-induced disturbance in the initial fields showed the Typhoon Haitang would still passed the area with a looping track. The channeling effect discussed by Jian and Wu (2008) is not a necessary condition for the looping motion to occur when a typhoon approaching Taiwan.

The important effect of the looping motion is that it dramatically changes the timing, the intensity, and the rainfall of the typhoon when it affects a region. Thus, it is very important to the hazard mitigation operation to accurately forecast the looping motion when a typhoon is approaching. Although such a looping motion east to Taiwan is relatively rare, it is worthwhile to examine the favorable conditions for this scenario to occur. Some additional simulations are currently being investigated to address this important hazard mitigation topic.

Acknowledgments This study was financially supported by the National Science Council of the R.O.C. under grants NSC94-2119-M-052-001-Ap1 and NSC95-2119-M-052-001-Ap1. The data and the computation resources were provided by the Central Weather Bureau. We are grateful for the help by Prof C.-C. $\mathrm{Wu}$ in conducting the piecewise potential vorticity inversion analysis. Constructive comments and suggestions from two reviewers are highly appreciated.

Open Access This article is distributed under the terms of the Creative Commons Attribution Noncommercial License which permits any noncommercial use, distribution, and reproduction in any medium, provided the original author(s) and source are credited.

\section{References}

Bender MA, Tuleya RE, Kurihara Y (1987) A numerical study of the effect of island terrain on tropical cyclones. Mon Weather Rev 115:130-155

Brand S, Blelloch J (1974) Changes in the characteristics of typhoons crossing the island of Taiwan. Mon Weather Rev 120:708-713

Chang SW (1982) The orographic effects induced by an island mountain range on propagating tropical cyclones. Mon Weather Rev 110:1255-1270

Chang SW (1983) A numerical study of the interaction between two tropical cyclones. Mon Weather Rev 112:1806-1817

Chen D-S, Huang K-N, Hsiao L-F, Yeh T-C, Cheng M-H (2006) The performance and evaluation of NFS model for the typhoon track prediction. Conference on weather analysis and forecasting. Central Weather Bureau, Taipei, pp 4-18-4-19

Davis CA (1992) Piecewise potential vorticity inversion. J Atmos Sci 49:1397-1411

Detering HW, Etling D (1985) Application of the E- $\varepsilon$ turbulence model to the atmospheric boundary layer. Boundary Layer Meteor 33:113-133

Grubisic V, Smith RB, Shar C (1995) The effect of bottom friction on shallow-water flow past an isolated obstacle. J Atmos Sci 52:1985-2005

Harshvardhan, Davies R, Randall DA, Corsetti TG (1987) A fast radiation parameterization for atmospheric circulation models. J Geophys Res 92:1009-1016

Hsiao L-F, Peng MS, Chen D-S, Huang K-N, Yeh T-C (2009) Sensitivity of typhoon track predictions in a regional prediction system to initial and lateral boundary conditions. J Appl Meteor Climatol 48:1913-1928

Hsiao L-F, Liou C-S, Yeh T-C, Guo YR, Chen D-S, Huang K-N, Terng C-T, Chen J-H (2010) A vortex relocation scheme for tropical cyclone initialization in advanced research WRF. Mon Weather Rev 138:3298-3315

Jian G-J, Wu C-C (2008) A numerical study of the track deflection of Supertyphoon Haitang (2005) prior to its landfall in Taiwan. Mon Weather Rev 136:598-615

Kuo HL (1974) Further studies of the parameterization of the influence of cumulus convection on large-scale flow. J Atmos Sci 31:1232-1240 
Kuo H-C, Williams RT, Chen J-H, Chen Y-L (2001) Topographic effects on barotropic vortex motion: no mean flow. J Atmos Sci 58:1310-1327

Kurihara Y, Bender MA, Tuleya RE, Ross RJ (1995) Improvements in the GFDL hurricane prediction system. Mon Weather Rev 123:2791-2801

Lander M, Holland GJ (1993) On the interaction of tropical-cyclone-scale vortices. I: observations. Q J R Meteorol Soc 119:1347-1361

Liao C-H (2006) Report on Typhoon 0505 (Haitang) of 2005. Meteorol Bull 46(2):63-88 (in Chinese with English abstract)

Lin Y-L, Han J, Hamilton DW, Huang C-Y (1999) Orographic influence on a drifting cyclone. J Atmos Sci 56:534-562

Lin Y-L, Chen S-Y, Hill CM (2005) Control parameters for the influence of a mesoscale mountain range on cyclone track continuity and deflection. J Atmos Sci 62:1849-1866

Liou C-S (2004) Improving forecast of rainfall and strong wind associated with typhoons approaching Taiwan. Technical Report MOTC-CWB-93-3M-01, pp. 23 (Available from the Central Weather Bureau)

Liou C-S, Chen J-H, Terng C-T, Wang F-J, Fong C-T, Rosmond TE, Kuo H-C, Shiao C-H, Cheng M-D (1997) The second-generation global forecast system at the Central Weather Bureau in Taiwan. Weather Forecast 12:653-663

Liou C-S, Sheng Y-F, Leou T-M, Lin S-C, Yeh T-C, Terng C-T, Chen D-S, Huang K-N, Chang M-Y (2009) A method of upgrading a hydrostatic model to a nonhydrostatic model. Terr Atmos Ocean Sci 20(5):727-739

Shapiro LJ (1996) The motion of Hurricane Gloria: a potential vorticity diagnosis. Mon Weather Rev 124:1497-2509

Shieh S-L, Wang S-T, Cheng M-D, Yeh T-C (1998) Tropical cyclone tracks over Taiwan from 1897 to 1996 and their application. Technical Report MOTC-CWB-86-1M-01, pp. 497 (in Chinese)

Smolarkiewicz P, Rasmussen RM, Clark TL (1988) On the dynamics of Hawaiian cloud bands: island forcing. J Atmos Sci 45:1872-1905

Ueyoshi K, Han Y-J (1991) A three-dimensional simulation of airflow and orographic rain over the island of Hawaii. J Meteor Soc Jpn 69:127-152

Wang S-T (1980) Prediction of the behavior and strength of typhoons in Taiwan and its vicinity. Research Report 108, National Science Council, Taipei, Taiwan, pp. 100 (in Chinese)

Wu C-C, Huang T-S, Chou K-H (2004) Potential vorticity diagnosis of the key factors affecting the motion of Typhoon Sinlaku (2002). Mon Weather Rev 132:2084-2093

Yeh T-C, Elsberry RL (1993a) Interaction of typhoons with the Taiwan orography. Part I: upstream track deflections. Mon Weather Rev 121:3193-3212

Yeh T-C, Elsberry RL (1993b) Interaction of typhoons with the Taiwan orography. Part II: continuous and discountinuous tracks across the island. Mon Weather Rev 121:3213-3233

Zhao Q, Black TL, Baldwin ME (1997) Implementation of the cloud prediction scheme in the eta model at NCEP. Weather Forecast 12:697-713 